\title{
Patient Safety in Undergraduate Radiography Curricula: A European Perspective
}

\author{
A. England $d^{\mathrm{a}, b^{*}}$, K.B. Azevedo ${ }^{\mathrm{a}, \mathrm{c}}$, P. Bezzina ${ }^{\mathrm{a}, \mathrm{d}}$, A. Henner ${ }^{\mathrm{a}, \mathrm{e}}$, J.P. McNulty ${ }^{\mathrm{a}, \mathrm{f}}$,
}

European Federation of Radiographer Societies, Catharijnesingel 73, 3511 GM Utrecht, The Netherlands

b Directorate of Radiography, School of Health Sciences, University of Salford, Allerton Building, Salford M5 4WT, United Kingdom

c Radiology Department, Centre for Health Studies, University of Algarve, Faro, Portugal

d Department of Radiography, Faculty of Health Sciences, University of Malta, Block A1, Mater Dei Hospital, Msida, MSD 2090, Malta

e School of Health and Social Care, Oulu University of Applied Sciences, Kiviharjuntie 8, FI-90220 Oulu, Finland

f Radiography and Diagnostic Imaging, School of Medicine, University College Dublin, Health Sciences Centre, Belfield, Dublin 4, Ireland

Andrew England (corresponding author)

Email: A.England@salford.ac.uk

Telephone: +441612950703

$\begin{array}{ll}\text { Kevin Azevedo } & \text { Email: kbazevedo@ualg.pt } \\ \text { Paul Bezzina } & \text { Email: paul.bezzina@um.edu.mt } \\ \text { Anja Henner } & \text { Email: Anja.Henner@oamk.fi } \\ \text { Jonathan P. McNulty } & \text { Email: jonathan.mcnulty@ucd.ie }\end{array}$




\section{Highlights}

- $\quad$ First European report on patient safety (PS)

- $\quad$ PS deeply embedded within curricula

- Terms and definitions largely consistent

- $\quad$ Some variety in the delivery and assessment methods

- $\quad$ Report provides baseline and opportunities for comparisons 


\begin{abstract}
Purpose: To establish an understanding of patient safety within radiography education across Europe by surveying higher education institutions registered as affiliate members of the European Federation of Radiographer Societies (EFRS).
\end{abstract}

Method: An online survey was developed to ascertain data on: programme type, patient safety definitions, relevant safety topics, specific areas taught, teaching and assessment methods, levels of teaching and curriculum drivers. Responses were identifiable in terms of educational institution and country. All 54 affiliated educational institutions were invited to participate. Descriptive and thematic analyses are reported.

Results: A response rate of $61.1 \%(n=33)$ was achieved from educational institutions representing 19 countries. Patient safety topics appear to be extremely well covered across curricula, however, topics including radiation protection and optimisation were not reported as being taught at an 'advanced level' by five and twelve respondents, respectively. Respondents identified the clinical department as the location of most patient safety-related teaching.

Conclusions: Patient safety topics are deeply embedded within radiography curricula across Europe. Variations exist in terms of individual safety topics included, teaching and assessment methods, and the depth in which subjects are taught. Results from this study provide a baseline for assessing developments in curricula and can also serve as a benchmark for comparisons.

\title{
Keywords
}

Assessment; curriculum; patient safety; radiation protection; radiography education; teaching methods 


\section{Introduction}

Patient safety is a major priority for all healthcare professions and is broadly defined as 'the prevention of harm to patients'. ${ }^{1}$ According to Vivekananda-Schmidt and Sandars undergraduate health professions education has the potential to improve patient safety. ${ }^{2}$ To support this, a number of guidance documents have been developed which aim to help support the introduction and promotion of patient safety within educational curricula. ${ }^{3-5}$ The role of patient safety topics within training curricula have become even more prominent following a number of high-profile cases and investigations such as the Mid-Staffordshire inquiry in the United Kingdom. ${ }^{6}$ As a result there have been increased emphasis upon inclusion of patient safety concepts within a variety of training curricula including medicine ${ }^{7,8}$, nursing ${ }^{7,9}$ and pharmacy $^{7}$ disciplines. Despite this increase there is a paucity of reports regarding the inclusion of patient safety topics within undergraduate radiography curricula.

Patient safety curricula have been developed by both global and national organisations. These include the World Health Organization (WHO) curriculum in patient safety ${ }^{10}$, the Australian Patient Safety Framework ${ }^{11}$ and the Canadian Patient Safety Institute Competency Framework. ${ }^{12}$ In Europe there is a growing number of radiography education providers, including universities, universities of applied sciences, technical institutes and vocational colleges. ${ }^{13}$ Despite this, there still remains a small number of countries where those clinically practicing in radiography have received very limited or even no formal training in diagnostic radiography or radiotherapy. ${ }^{14,15}$

With patient safety being such an important topic, together with the potential for significant variation across Europe, the aim of this European Federation of Radiographer Societies (EFRS) project was to evaluate and report the inclusion of patient safety within undergraduate radiography curricula across Europe.

\section{Materials and methods}

Design

The research design was an online survey using a questionnaire developed by the EFRS Educational Wing. The focus of the questionnaire was key issues surrounding patient safety pertinent to radiography education. The questionnaire included open and closed questions and consisted of sections designed to ascertain patient safety data. Such questions included: programme type (one question), patient safety definitions (two questions), relevant safety 
topics (one question), specific areas taught (seventeen questions), teaching and assessment methods (two questions), levels of teaching (one question) and relevant curriculum drivers (one question).

Following development, the questionnaire was piloted using a small group of native and nonnative English speakers, who were from within and outside the profession, and none of whom would be in the target distribution group. A number of suggestions were received from the pilot and the questionnaire was revised according. The majority of the amendments related to the time commitment required to complete the questionnaire and the wording of certain questions, especially for non-native English speakers. All respondents consented to data being identifiable in terms of educational institution and country. SurveyMonkey® Gold (Palo Alto, USA) was used to develop and deploy the online survey with backtracking not permitted between sections in the survey.

\section{Participants}

All 54 educational institutions, that were EFRS affiliate members (full membership of the EFRS is open to national societies whereas educational institutions offering radiography programmes may join as affiliate members), were invited to complete this online survey between the $3^{\text {rd }}$ of June 2016 and the $17^{\text {th }}$ of June 2016. An initial response deadline of two weeks was stated and two follow-up emails were sent to non-responding institutions with a final closing date of the $6^{\text {th }}$ of July 2016.

\section{Data analysis}

All data were uploaded to IBM SPSS Statistics Version 23 (Armonk, USA). Descriptive statistics are reported for most analyses while open questions were examined using thematic analysis.

\section{Results}

Upon review of the responses duplicates existed from two institutions and the response from the named EFRS link tutor was selected where this situation arose. Responses were received from 33 of the 54 educational institutions giving a response rate of $61.1 \%$, representing 19 countries. The educational institutions that participated in this survey are listed in Table 1. A coding system, based on the International Organization of Standards (ISO) country codes, has been utilised in order to identify participants against the relevant results.

Commented [JN1]:

Could you expand on the difference in education provision across the countries, l.e levels - potentially referring to McNulty et al 2015? N.B. Was there any link to level and PS inclusion?

Commented [12]: While we do have data on the level of the programmes among our affiliate members i.e. EQF level 5 or 6 we did not capture this data in the current survey and thus have not did not capture this data in the
presented it in our results. 
Table 1. Responding educational institutions $(n=33)$

\begin{tabular}{|c|c|c|c|c|c|}
\hline Country & Institution & $\begin{array}{l}\text { Cod } \\
\text { e }\end{array}$ & Country & Institution & Code \\
\hline Austria & FH Campus Wien ${ }^{a}$ & AT1 & Latvia & $\begin{array}{l}\text { Pauls Stradiňš } \\
\text { University Hospital }^{\text {b,d }} \\
\end{array}$ & LV2 \\
\hline Austria & FH Wiener Neustadt ${ }^{\mathrm{a}}$ & AT2 & Lithuania & Klaipeda University ${ }^{\mathrm{a}}$ & LU1 \\
\hline Belgium & Institut Paul Lambin ${ }^{\mathrm{b}, \mathrm{d}}$ & BE1 & Malta & University of Malta $^{\mathrm{e}}$ & MT1 \\
\hline Belgium & Odisee UoAS ${ }^{a}$ & BE2 & Netherlands & INHollland UoAS ${ }^{\mathrm{a}}$ & NL1 \\
\hline $\begin{array}{l}\text { Czech } \\
\text { Republic }\end{array}$ & $\begin{array}{l}\text { University of West } \\
\text { Bohemia }^{\mathrm{a}}\end{array}$ & $\mathrm{CZ1}$ & Netherlands & Hanze UoAS ${ }^{\text {a }}$ & NL2 \\
\hline Denmark & $\begin{array}{l}\text { University College } \\
\text { Lillebelt }^{\mathrm{a}}\end{array}$ & DK1 & Norway & $\begin{array}{l}\text { Høgskolen i Bergen } \\
\text { University College }^{\mathrm{b}}\end{array}$ & NO1 \\
\hline Estonia & $\begin{array}{l}\text { Tartu Health Care } \\
\text { College }^{\mathrm{a}}\end{array}$ & EE1 & Portugal & $\begin{array}{l}\text { Escola Superior de } \\
\text { Tecnologia da Saúde } \\
\text { de Lisboa }^{\text {a }}\end{array}$ & PT1 \\
\hline Finland & Oulu UoAS ${ }^{\mathrm{a}}$ & FI1 & Portugal & $\begin{array}{l}\text { University of the } \\
\text { Algarve }^{\mathrm{a}}\end{array}$ & PT2 \\
\hline Finland & Turku UoAS ${ }^{a, b, c, d}$ & FI2 & Portugal & $\begin{array}{l}\text { CESPU Cooperativa } \\
\text { de Ensino Superior }{ }^{b}\end{array}$ & PT3 \\
\hline Finland & $\begin{array}{l}\text { Helsinki Metropolia } \\
\text { UoAS }^{\text {a }}\end{array}$ & FI3 & Slovenia & $\begin{array}{l}\text { University of } \\
\text { Ljubljana }^{\mathrm{a}} \\
\end{array}$ & SL1 \\
\hline Finland & Savonia UoAS & FI4 & Sweden & Örebro University ${ }^{\mathrm{b}}$ & SE1 \\
\hline France & ISTM Valence ${ }^{\mathrm{a}}$ & FR1 & Sweden & $\begin{array}{l}\text { Jönköping School of } \\
\text { Health Sciences }\end{array}$ & SE2 \\
\hline Greece & $\begin{array}{l}\text { Technical University of } \\
\text { Athens }{ }^{\text {a }}\end{array}$ & GR1 & $\begin{array}{l}\text { United } \\
\text { Kingdom }\end{array}$ & Ulster University $\mathrm{b}, \mathrm{c}$ & UK1 \\
\hline Ireland & $\begin{array}{l}\text { University College } \\
\text { Dublin }^{\mathrm{b}}\end{array}$ & IE1 & $\begin{array}{l}\text { United } \\
\text { Kingdom }\end{array}$ & $\begin{array}{l}\text { London Southbank } \\
\text { University }{ }^{\mathrm{b}, \mathrm{c}}\end{array}$ & UK2 \\
\hline Italy & $\begin{array}{l}\text { University of Bologna }{ }^{a, b}, \\
c, d, e\end{array}$ & IT1 & \begin{tabular}{|l|} 
United \\
Kingdom \\
\end{tabular} & University of Salford ${ }^{\mathrm{b}}$ & UK3 \\
\hline Italy & University of Turin ${ }^{b, c, d}$ & IT2 & \begin{tabular}{|l} 
United \\
Kingdom
\end{tabular} & $\begin{array}{l}\text { Robert Gordon } \\
\text { University }^{\mathrm{b}} \\
\end{array}$ & UK4 \\
\hline Latvia & University of Latvia $^{a}$ & LV1 & & & \\
\hline
\end{tabular}

${ }^{a}$ combined medical imaging, radiotherapy and nuclear medicine programme; ${ }^{b}$ separate

medical imaging programme; ${ }^{\mathrm{c}}$ separate radiotherapy programme; ${ }^{\mathrm{d}}$ separate nuclear medicine programme; ${ }^{\text {e }}$ combined medical imaging and radiotherapy programme but without nuclear medicine.

\section{Respondents}

Of the respondents, 20 (60.6\%) currently deliver combined medical imaging (MI), radiotherapy (RT) and nuclear medicine (NM) programmes i.e. all three branches covered in the one entry-
Commented [JN3]:

Table 1. May be a little pedantic but why has GB been used as an acromym when United Kingdom is listed as country, is it to do with EU codes? In which case should Great Britain (+/- NI) be used as the country name?

Commented [14]: Updated to 'UK'. These are based on the ISO system and up until last year the UK was still listed as GB in the system!
Commented [JN5]:

P5 respondents line 1 , by combined programme do you mean qualifies the individual as a diagnostic/ therapeutic radiographer or that the institution runs both programmes? 
level programme . Seven institutions (IE1, NO1, PT3, SE1, SE2, UK3 and UK4) only delivered dedicated MI programmes. Two institutions (MT1 and UK1) delivered combined MI and RT programmes without NM.

\section{Defining patient safety}

When the respondents were asked to provide free text on their understanding of 'Patient Safety' the most frequently used words were patient, safety, radiation and care. When asked to select the three patient safety definitions most relevant to their institution, using a pre-specified list (some defined by the project team and others taken from definitions used by the WHO and other international organisations), the responses received are described in Table 2. Statement $\mathrm{C}$ 'Reducing the incidence of unnecessary disease, injuries, adverse events and deaths caused to patients through the delivery of therapeutic or diagnostic procedures' was identified as the single most relevant definition (45.5\% of respondents). The least favoured definition was Statement E 'Ability to allow patients to participate in their own healthcare through advancement in decision making' (18.2\% of respondents). Participants were invited to select the three patient safety definitions most relevant to their institution, which was the combination of Statements B, C and D selected by 12 (36.4\%) institutions (AT1, AT2, BE1, MT1, UK4, IT1, IE1, DK1, GR1, CZ1, LV1 and FI2).

\section{Table 2. Patient safety definitions most relevant to the respondent's institution}

\begin{tabular}{|c|c|c|}
\hline & Definition & n (\%) \\
\hline A. & Delivery of healthcare without any kind of error based on safe processes & $15(45.5)$ \\
\hline B. & $\begin{array}{l}\text { The absence of preventable harm to a patient during the process of healthcare } \\
\text { through the coordinated efforts to prevent harm, cause by the process of healthcare } \\
\text { itself, from occurring to patients. }\end{array}$ & $21(63.6)$ \\
\hline C. & $\begin{array}{l}\text { Reducing the incidence of unnecessary disease, injuries, adverse events and deaths } \\
\text { caused to patients through the delivery of therapeutic or diagnostic procedures. }\end{array}$ & $26(78.8)$ \\
\hline D. & $\begin{array}{l}\text { A safe healthcare environment based on having access to the best technology } \\
\text { available, the best trained professionals, the best designed healthcare processes and } \\
\text { facilities. }\end{array}$ & $25(75.8)$ \\
\hline E. & $\begin{array}{l}\text { Ability to allow patients to participate in their own healthcare through advancement } \\
\text { in decision making. }\end{array}$ & $6(18.2)$ \\
\hline $\mathrm{F}$ & $\begin{array}{l}\text { Always doing the right thing, always speaking up if something is wrong, and } \\
\text { always double checking all procedural steps. }\end{array}$ & $8(24.2)$ \\
\hline & n, number of respondents. & \\
\hline
\end{tabular}

Commented [16]: Inserted in an effort to clarify this.

\section{Commented [JN7]:}

P6 para 1. Where did the definitions come from, were they researcher derived or from another resource?

Commented [18]: Added to clarify the above 


\section{Patient safety topics}

All institutions ( $\mathrm{n}=33)$ considered both "Radiation Protection" and "Contrast Agents" as patient safety related topics. Responses for the other topics presented to the respondents under the umbrella of patient safety were all identified by at least $80 \%$ of institutions (Table 5). Five (15.2\%) institutions did not consider patient preparation checks surrounding radiotherapy to be including in their training curricula. Of which four were Programmes without RT (UK 4, PT3,

IE1 and BE1) and one was a combined MI, RT and NM Programme (NL2). Staff health was considered as a patient safety topic by the fewest institutions $(25,75.8 \%)$. Those which did not include this topic within their training curricula were the institutions PT3, IE1, FR1, BE2, NL2, PT1, IT2 and LV1.

\section{Patient safety in the curriculum}

Respondents were next invited to provide specific details regarding individual patient safety areas taught as part of their radiography programme. The responses by the participants are provided in Tables 3 and 4 . 
Table 3. Respondents were asked "Does your institution teach or provide...."

\section{Radiation Protection}

the different effects associated with ionising radiation?

how to protect patients from ionising radiation?

how to minimise the radiation exposure of the patient and the carer?

Justification

the concept of justification?

specific training so that radiographers are able to justify radiographic examinations upon qualification?

students to suggest how to approach justification decisions in clinical practice?

the importance of reading all clinical information for the justification of a given exam or procedure?

Optimisation

the ALARA principle?

the concept of dose optimisation?

the importance of reading all clinical information for the optimisation of a given exam or procedure?

Intravenous cannulation

your students how to cannulate patients?

the risks associated with cannulation and care of cannulas?

how to manage extravasation?

your students about maximal flow rates based on catheter diameters?

\section{Contrast agents}

about all contrast agent types?

what are mild, moderate and severe reactions to contrast agents and how to recognise these?

how to react to each type of reaction?

cardiopulmonary resuscitation and basic life support?

Drug Administration

pharmacology and drug administration routes?

how to properly store, handle, and dispose of different types of drug?

possible side effects and toxicity of the drugs commonly used in an imaging department?

aspects of safe prescribing drugs?

Moving (lifting) and handling, fall prevention

the safe moving and handling of patients?

specialist moving and handling e.g. unconscious patients, spinal injuries, etc?

how to identify patients that might be at risk of falls?

the use of clinical scales assessing the risk of a fall?

\section{MRI Safety}

about MR safety issues beyond the scan room?

about the risks associated with the main magnet / static magnetic field and the risks associated with the time varying gradient magnetic field?

about the risks associated with the RF system, RF deposition and SAR?

about the risks associated with Gadolinium-based contrast agents?

\begin{tabular}{|c|c|}
\hline \multicolumn{2}{|c|}{ n (\%) } \\
\hline Yes & $\begin{array}{c}\text { Future } \\
\text { curricula }\end{array}$ \\
\hline $33(100.0)$ & $0(0.0)$ \\
\hline $33(100.0)$ & $0(0.0)$ \\
\hline $33(100.0)$ & $0(0.0)$ \\
\hline $33(100.0)$ & $0(0.0)$ \\
\hline $26(78.8)$ & $3(9.1)$ \\
\hline 27 (81.8) & $5(15.2)$ \\
\hline $29(87.9)$ & $4(12.1)$ \\
\hline $33(100.0)$ & $0(0.0)$ \\
\hline $33(100.0)$ & $0(0.0)$ \\
\hline $33(100.0)$ & $0(0.0)$ \\
\hline $26(78.8)$ & $5(15.2)$ \\
\hline $28(84.8)$ & $2(6.1)$ \\
\hline $27(81.8)$ & $2(6.1)$ \\
\hline $27(81.8)$ & $3(9.1)$ \\
\hline $33(100.0)$ & $0(0.0)$ \\
\hline $33(100.0)$ & $0(0.0)$ \\
\hline $33(100.0)$ & $0(0.0)$ \\
\hline $33(100.0)$ & $0(0.0)$ \\
\hline $29(87.9)$ & $1(3.0)$ \\
\hline $24(72.7)$ & $2(6.1)$ \\
\hline $29(87.9)$ & $1(3.0)$ \\
\hline $19(57.6)$ & $3(9.1)$ \\
\hline $32(97.0)$ & $0(0.0)$ \\
\hline $31(93.9)$ & $0(0.0)$ \\
\hline $26(78.8)$ & $2(6.1)$ \\
\hline $12(36.4)$ & $2(6.1)$ \\
\hline $33(100.0)$ & $0(0.0)$ \\
\hline $33(100.0)$ & $0(0.0)$ \\
\hline $32(97.0)$ & $0(0.0)$ \\
\hline $32(97.0)$ & $0(0.0)$ \\
\hline
\end{tabular}

$\mathrm{n}$, number of respondents; RF, radiofrequency; SAR, specific absorption rate. 
Table 4. Respondents were asked "Does your institution teach or provide...."

\begin{tabular}{|c|c|c|}
\hline \multirow[b]{2}{*}{ Nosocomial infection and cross-infection control } & \multicolumn{2}{|c|}{$\mathbf{n}(\%)$} \\
\hline & Yes & $\begin{array}{c}\text { Future } \\
\text { curriculum }\end{array}$ \\
\hline what is nosocomial infection and how to control cross infection? & $31(93.9)$ & $1(3.0)$ \\
\hline methods to help prevent the cross-infection such as hand hygiene? & $33(100.0)$ & $0(0.0)$ \\
\hline what is an isolated patient and how to interact with isolated patients? & $31(93.9)$ & $1(3.0)$ \\
\hline how to interact with respiratory isolated patients? & $31(93.9)$ & $1(3.0)$ \\
\hline \multicolumn{3}{|l|}{ Staff Health } \\
\hline the importance of employee health and up to date immunisations with respect to patient safety? & $24(72.7)$ & $2(6.1)$ \\
\hline that professionals should take measures when they catch a transmittable disease such as flu? & $27(81.8)$ & $2(6.1)$ \\
\hline how to cough and sneeze properly to minimise transmission risks? & $26(78.8)$ & $2(6.1)$ \\
\hline \multicolumn{3}{|l|}{ Patient identification } \\
\hline the importance of correctly identifying a patient? & $32(97.0)$ & $1(3.0)$ \\
\hline the importance of, and techniques for, establishing identification in uncooperative or unconscious patients? & $31(93.9)$ & $2(6.1)$ \\
\hline strategies to correctly identify all patients such as a three point identification check? & $22(66.7)$ & $5(15.2)$ \\
\hline \multicolumn{3}{|l|}{ Effective communication } \\
\hline the theory on communication processes? & $33(100.0)$ & $0(0.0)$ \\
\hline strategies to communicate clearly and effectively? & $32(97.0)$ & $1(3.0)$ \\
\hline strategies to properly handover a patient to other staff? & $25(75.8)$ & $5(15.2)$ \\
\hline strategies to properly handover at the end of a shift? & $23(69.7))$ & $5(15.2)$ \\
\hline \multicolumn{3}{|l|}{ Error reporting and analysis } \\
\hline what is meant by 'errors' in healthcare? & $27(81.8)$ & $3(9.1)$ \\
\hline the importance of reporting an error as soon as possible? & $32(97.0)$ & $1(3.0)$ \\
\hline that error reports are useful in preventing future errors and in organisational learning? & $28(84.8)$ & $2(6.1)$ \\
\hline about the analysis and discussion of error reports? & $27(81.8)$ & $3(9.1)$ \\
\hline \multicolumn{3}{|l|}{ Confidentiality and Data Protection } \\
\hline the laws regarding confidentiality issues and data protection in use in your country? & $33(100.0)$ & $0(0.0)$ \\
\hline on how electronic patient data should be managed and distributed? & $31(93.9))$ & $1(3.0)$ \\
\hline on how paper based patient data should be managed an distributed? & $28(84.8)$ & $0(0.0)$ \\
\hline the value of understanding patient data in terms of developing safer systems of work e.g. audit? & $26(78.8)$ & $2(6.1)$ \\
\hline \multicolumn{3}{|l|}{ Team working } \\
\hline the importance of working as part of a team in healthcare? & $33(100.0)$ & $0(0.0)$ \\
\hline students ways to work as part of a team? & $30(90.9)$ & $1(3.0)$ \\
\hline $\begin{array}{l}\text { students way to resolve interpersonal conflicts? } \\
\text { regularly undertake teaching as part of multidisciplinary groups e.g. radiographers, nurses, physiotherapists, } \\
\text { etc? }\end{array}$ & $\begin{array}{l}26(78.8) \\
23(69.7)\end{array}$ & $\begin{array}{l}3(9.1) \\
3(9.1)\end{array}$ \\
\hline \multicolumn{3}{|l|}{ Child Protection } \\
\hline the role of the radiographer in child protection cases e.g. when abuse is suspected? & $33(100.0)$ & $0(0.0)$ \\
\hline the laws regarding child protection in use in your country? & $28(84.8)$ & $1(3.0)$ \\
\hline $\begin{array}{l}\text { students the role of the radiographer in managing examinations of procedures when abuse is suspected or } \\
\text { when a child starts disclosing information? }\end{array}$ & $27(81.8)$ & $1(3.0)$ \\
\hline \multicolumn{3}{|l|}{ Radiotherapy (checks in relation to appropriate patient preparation) } \\
\hline about the importance of bladder status for PC patients and breath holding for $\mathrm{BC}$ patients? & $24(72.7)$ & $2(6.1)$ \\
\hline effective immobilisation techniques? & $25(75.8)$ & $2(6.1)$ \\
\hline about daily protocol checks in terms of reproducibility of the treatment plan? & $23(69.7)$ & $2(6.1)$ \\
\hline about the assessment of patients' condition in relation to the site being treated? & $24(72.7)$ & $2(6.1)$ \\
\hline
\end{tabular}


Teaching methods used in the curriculum

A small number of topics were not taught by some institutions and these included intravenous cannulation (4, [12.1\%] UK 3, NL1, IT2 and GR1), drug administration (3, [9.1\%] UK 3, NL2 and IT2), moving (lifting) and handling (1, [3.0\%] PT3), staff health (3, [9.1\%] PT3, NL1 and LV1), patient identification (1, [3.0\%] LU1) and radiotherapy (patient preparation checks) (7, [21.2\%] SE1, UK 3, UK 4, PT3, SE2, IE1 and BE1). Respondents were asked to indicate the different teaching methods used for the delivery of patient safety topics within their curricula; classroom based activities were the most common in 30 (90.9\%) institutions whereas online based methods were the least utilised $(4,12.1 \%)$. Illustrations of the frequencies of the different teaching methods utilised, according to the individual patient safety topic, are detailed in Figure 1.

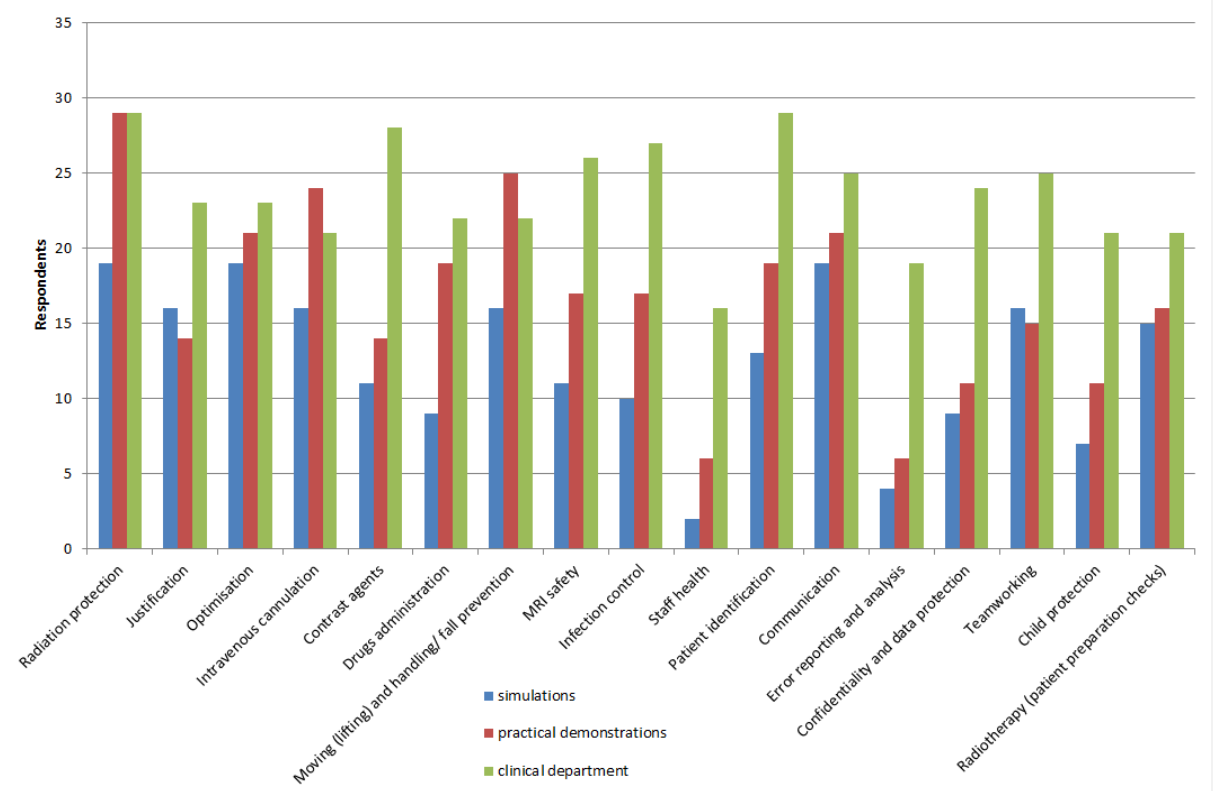

Figure 1. Utilisation of simulation, practicals and clinical department based teaching methods according to patient safety topic

Patient safety teaching levels across the curriculum

Respondents were asked to indicate the level in which different patient safety topics were taught within their curricula (Table 5). The term 'introduced' indicates that the students have had an initial introduction to the topic; 'Further developed' was used as an indicator that the 
topic has been developed / reinforced and students potentially have the opportunity to apply knowledge; and teaching at an 'advanced' level was used to indicate that the students should now demonstrate advanced knowledge, skills and competence and mastery of the topic. Topics in which over half of the respondents indicated were being taught at advanced level included radiation protection $(84.5 \%)$, optimisation $(62.5 \%)$, MRI safety $(65.6 \%)$, patient identification $(65.5 \%)$ and communication $(53.1 \%)$. All topics were taught at an advanced level by at least one institution. The three commonest topics taught at an introductory level were error reporting and analysis (37.5\%), drug administration (34.4\%) and staff health (34.4\%).

Table 5. Teaching Levels for Patient Safety Topics across Europe

\begin{tabular}{lcccc}
\hline & \multicolumn{3}{c}{ n (\%) } \\
\cline { 2 - 5 } Teaching level & Introduced & Further developed & Advanced level & Not taught \\
\hline Radiation protection & $0(0.0)$ & $5(15.6)$ & $27(84.5)$ & $0(0.0)$ \\
Justification & $4(12.5)$ & $13(40.6)$ & $15(46.9)$ & $0(0.0)$ \\
Optimisation & $4(12.5)$ & $8(25.0)$ & $20(62.5)$ & $0(0.0)$ \\
Intravenous cannulation & $7(21.9)$ & $13(40.6)$ & $8(25.0)$ & $4(12.5)$ \\
Contrast agents & $2(6.3)$ & $17(53.1)$ & $13(40.6)$ & $0(0.0)$ \\
Drugs administration & $11(34.4)$ & $13(40.6)$ & $6(18.8)$ & $2(6.3)$ \\
Moving (lifting) and handling/ fall prevention & $4(12.5)$ & $13(40.6)$ & $14(43.6)$ & $1(3.1)$ \\
MRI safety & $2(6.3)$ & $9(28.1)$ & $21(65.6)$ & $0.0(0.0)$ \\
Infection control & $4(12.5)$ & $14(43.8)$ & $14(43.8)$ & $0(0.0)$ \\
Staff health & $11(34.4)$ & $13(40.6)$ & $5(15.6)$ & $3(9.4)$ \\
Patient identification & $1(3.1)$ & $9(28.1)$ & $21(65.5)$ & $1(3.1)$ \\
Communication & $5(15.6)$ & $10(31.3)$ & $17(53.1)$ & $0(0.0)$ \\
Error reporting and analysis & $12(37.5)$ & $15(46.9)$ & $5(15.6)$ & $0(0.0)$ \\
Confidentiality and data protection & $4(12.5)$ & $14(43.8)$ & $14(43.8)$ & $0(0.0)$ \\
Team working & $4(12.5)$ & $16(50.0)$ & $11(34.4)$ & $1(3.1)$ \\
Child protection & $8(25.0)$ & $12(37.5)$ & $12(37.5)$ & $0(0.0)$ \\
Radiotherapy (patient preparation checks) & $3(9.4)$ & $7(21.9)$ & $15(46.9)$ & $7(21.9)$ \\
\hline n, number of respondents. & & & \\
\hline
\end{tabular}

\section{Assessment of patient safety topics within the curriculum}

Respondents were asked to indicate how patient safety concepts were assessed within their training curricula. Options available included classroom based examinations, coursework, clinical (hospital) assessments, skills labs based assessments or that the topic was not assessed. Depending on the individual topic there was a wide range in the assessment methods used by responding institutions (Fig 2). 


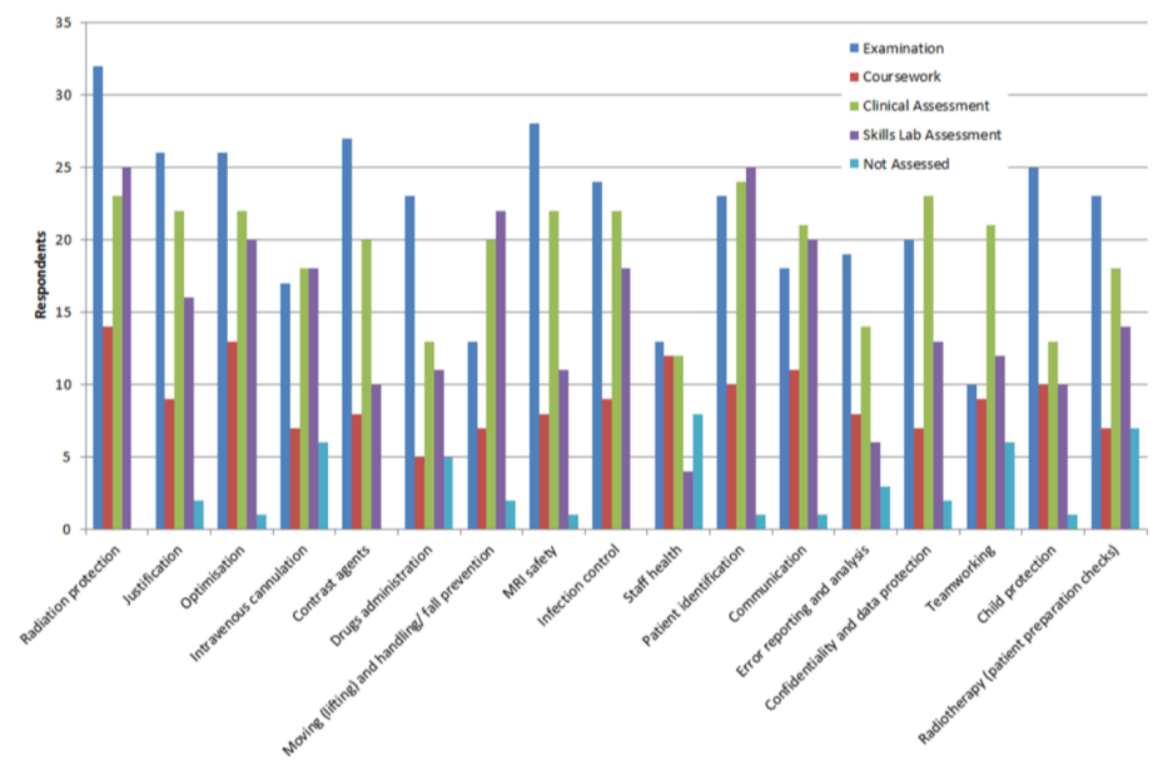

Figure 2. Methods of assessment used for evaluation patient safety topics within the curriculum

\section{Drivers for inclusion of patient safety topics within the curriculum}

Participants were asked to identify key drivers for including patient safety within their curricula. Various options were available (Table 6), national guidance documents were considered by the majority to be most influential factor (31, 93.9\% of institutions) in dictating the inclusion of patient safety topics within the curriculum. The least influential factor were local needs (2, $6.1 \%$ of responding institutions).

Table 6. Drivers for including patient safety topics within radiography curricula

\begin{tabular}{lc}
\hline Drivers & $\mathbf{n}(\boldsymbol{\%})$ \\
\hline National legislation & $31(93.9)$ \\
European legislation & $25(75.8)$ \\
National guidelines & $28(84.8)$ \\
International guidelines & $22(66.7)$ \\
Regulatory requirements & $26(78.8)$ \\
Local needs & $2(6.1)$ \\
\hline n, number of respondents. & \\
\hline
\end{tabular}




\section{Discussion}

National and international organisations have made significant attempts to increase the inclusion of patient safety within healthcare training curricula. ${ }^{2-5,10-12}$ For radiographers, educators and their professional bodies two distinct questions remain, namely, 1) the overall degree of inclusion of patient safety within educational curricula and 2) the levels of variation both between and within national borders. Within this EFRS survey, data was obtained from 33 affiliate members spanning across 19 European countries. The response rate of $61.1 \%$ was favourable in terms of online questionnaires ${ }^{16}$ but lower than a previous EFRS educational study $(89.1 \%) .{ }^{13}$ As far as the authors are aware, this is the first survey of patient safety concepts specifically within radiography education, which incorporates medical imaging, radiotherapy and nuclear medicine sub-disciplines.

Our study shows that across Europe there is fairly widespread agreement regarding the concept of patient safety, as one third of respondents selected the same group of three patient safety definitions. Almost half of the responding institutions indicated that the "delivery of healthcare without any kind of error based on safe processes" was their preferred patient safety definition. A high level of agreement also existed in selecting safety topics that would be included under the banner of patient safety. Both radiation protection and contrast agents were considered topics by all institutions. All of the remaining 16 topics were considered under the patient safety umbrella by at least three-quarters of institutions (Tables 3 and 4). It is perhaps unsurprising that high levels of inclusivity exist as patient safety has been the forefront of many high profile national/international guidance documents $\mathrm{s}^{3-5,10-12}$ and regularly forms the focus of professional debates at conferences. In the future it is likely that we will see further institutions adopting the current spectrum of patient safety topics within their programmes. It is also likely that we will see new topics enter our curricula.

It is perhaps reassuring that radiation protection, including justification and optimisation, are taught in nearly all institutions. This is important with the introduction of the new EC Basic Safety Standard (BSS) Directive, ${ }^{17}$ from the survey we also have some evidence that students will be equipped with the skills necessary to deliver the changes in EU legislation. From the detailed responses in Table 5, it is also clear that further development of justification in the curriculum is planned by five $(15 \%)$ institutions.

Both staff health $(75.8 \%)$ and team working $(81.8 \%)$ were the least included topics in training curricula (Table 4). It is possible that both of these topics are taught but the responding 
institution did not consider that they fell under the remit of patient safety. A limitation of the study questionnaire was that it did not seek to ascertain which subjects were taught within other aspects of the curriculum. By way of an example, in Ireland and the UK, staff health and team working would be taught under fitness to practise and core skills ${ }^{18,19}$ and it would be based on the respondent's interpretation as to whether they were reported as patient safety topics.

Within the detailed responses provided in Tables 3 and 4 there is evidence that patient safety topics will be included in future curricula developments. The most common areas, outside of radiation protection, include intravenous cannulation, patient identification and patient handovers. Such changes are likely to represent both the developing role of the radiographer and also changing trends in how radiography is practiced.

In terms of teaching provision, traditional classroom based activities i.e. lectures dominate radiography curricula in terms of the delivery of patient safety concepts. Both radiation protection and infection control utilise online methods in more instances that any other patient safety topics. Reasons for this are likely to be multifactorial, however, one reason could be that these topics are likely to be accessed by other health professionals and thus online content may provide a more flexible set of teaching resources. With developments in technology and the demands from both students and healthcare providers, it is likely that there will be greater demand for online content in future years.

When considering the utilisation of clinical training, practicals and simulation for patient safety concepts (Fig. 1) there is a consistent dominance by the clinical department-based teaching. It is likely that there are a number of reasons to explain this; 1) clinical (department based) training generally occupies a large proportion of the timetable and as such it may provide the most frequent opportunity for students to learn; 2) when learning about patient safety it is necessary to have hands-on experience of patients and there is no better place for this than within the clinical department. Practical demonstrations provide an opportunity for learning for all topics but not with the same frequency as the clinical department. It would have been interesting to stratify the learning activity according to the year of study as in many programmes it would be the norm to learn and practice within the institution's skills lab before coming face to face with patients. A further trend is the emergence of simulation as an option for learning. Access to quality simulations has resource implications and also requires their careful implementation within curricula, however, it is likely that we will see an increase in the utilisation of simulation in the future. ${ }^{20,21}$ 
It is reassuring that radiation protection is taught at either a 'further developed' or 'advanced level' in all institutions. Indeed, this was the trend for a large number of patient safety topics (Table 5). Those which were only taught at an 'introductory' level or not taught by greater than $20 \%$ of respondents were intravenous cannulation, drug administration, staff health, error reporting and analysis, and child protection. Reasons to explain this could be that several of the topics would fit within the area of advanced or extended scope of practice (intravenous cannulation / drug administration), facilities are not available (error reporting and analysis) and that the topics could be taught under different areas of the curriculum (child protection, staff health). Topics including radiation protection and optimisation were not reported as being taught at an 'advanced level', by five and twelve respondents respectively, which is somewhat unusual as these are core responsibilities for radiographers.

In terms of assessment, as would be expected there was a wide range in the assessment strategies reported. Unsurprisingly, the dominant assessment method was a traditional examination and this is likely to be the result of historical practices, regulatory requirements, and institutional logistics amongst others. The second most dominant assessment method was in clinical practice; which is encouraging as from a patient safety perspective it is important to ascertain competency on patients. A large number of topics were not assessed by some institutions (Fig. 2) and reasons are likely to be diverse and multifactorial.

The survey sought the opinion of the respondents regarding the drivers for including patient safety within curricula. The most frequent reason (94\%) was national legislation and this was perhaps unsurprising given that professional registration and licensing is dictated at national levels. The second biggest driver was European legislation, as in many instances European developments will filter into national legislation. It was also clear from the survey that numerous drivers are responsible for the inclusion of patient safety within undergraduate curricula and it is likely that the influence of curriculum drivers will change depending on the subject.

While the current study explores the patient safety-related topics covered in undergraduate radiography curricula, it does not explore the importance of effective communication skills. Ineffective communication poses a significant risk in terms of patient safety ${ }^{6,10}$ and patients also have a right to be, and expect to be, fully informed when it comes to all diagnostic examinations and therapeutic procedures. ${ }^{22,23}$ The WHO have identified the need to address 
the potential education and training gap in benefit-risk communication among all healthcare professionals involved in diagnostic procedures. ${ }^{10,24}$ This is especially important for radiographers and radiologists who often have a short amount of time to gain the trust and confidence of their patients. ${ }^{24,25}$ Such approaches can reduce unnecessary examinations being performed, provide patients with an improved understanding of the risks associated with procedures, and reduce risk. ${ }^{23,24,26}$ Worryingly, research has shown that, despite advanced levels of education and training in the area of radiation protection, radiographers and radiologists often lack the confidence to discuss risk with their patients. ${ }^{26,27}$

\section{Limitations}

As previously acknowledged our response rate of $61.1 \%$ was lower than a previous EFRS survey. ${ }^{13}$ As a result, one third of member institutions were not represented in this survey and this will have some implications in the generalisability of our findings across Europe. Our results do incorporate responses from 19 of the 24 countries represented by the Educational Wing of the EFRS ${ }^{28}$ and have provided the first opportunity to describe the inclusion of patient safety within radiography education. A lower than expected response rate may reflect the summer data collection period and this should be given consideration in future surveys.

Radiography education is constantly evolving, newer courses are being accredited and existing courses are being developed in order to reflect demands from regulatory bodies, clinical departments, students and educational institutions. Our study provides valuable information on patient safety in the curriculum but only presents data from a single snapshot in time. Our study did not seek to capture the rate of change in including patient safety topics in radiography curricula which could be dramatic given the current position of this subject within public and professional debates.

The issue of validation could be raised when considering our results. Data collection relied on a single person completing an online questionnaire for each affiliate member. The correctness of individual responses would have some dependency on the individual's understanding of the English language and their knowledge of their own institution's curricula. We accept that there are mechanisms which could have tested the validity of the collected data including follow-up interviews and the detailed interrogation of programme specifications and module/study unit descriptors. Our decision not to undertake these additional approaches was based on a number of factors including the time available to complete this study. We would argue that by engaging with the EFRS, and representing their institution, the respondent had indicated that they were 
conversant with the English language and that they were in a suitable position to have good understanding of their respective curricula.

\section{Conclusion}

From this study it has been demonstrated that patient safety is a deeply embedded concept within undergraduate radiography curricula across Europe. Variations do exist in the individual topics included, the teaching and assessment methods, and the depth or level in which subjects are taught. This study provides a useful baseline in order to evaluate developments in curricula over time. Radiography educators can also use the results of this EFRS survey in order to compare their curricula against those within comparator European countries.

\section{Conflict of interest}

No conflict of interest.

\section{Acknowledgements}


We acknowledge the contribution of those who participated in the pilot study and the continued support and contribution of the educational institutions who are EFRS affiliate members and to the individuals who participated in this survey.

\section{References}

1. Aspden P., Corrigan J., Wolcott J. Patient safety: achieving a new standard of care. Washington, DC: National Academies Press; 2004. 
2. Vivekananda-Schmidt, P., Sandars, J. Developing and implementing a patient safety curriculum. Clin Teach 2016;13:91-97.

3. WHO Patient Safety Curriculum Guide for Medical Schools 2009. Available from http://www.who.int/patientsafety/education/curriculum/en/index.html [accessed 09.09.16].

4. WHO Patient Safety Curriculum Guide for Medical Schools: A Summary 2009. Available from http://www.who.int/patientsafety/education/curriculum/en/index.html [accessed 09.09.16].

5. Australian Patient Safety Education Framework, (APSEF) 2005. Available from http://www.health.gov.au/internet/safety/publishing.nsf/content/

CO6811AD746228E9CA2571C600835DBB/\$File/framework0705.pdf [accessed 09.09.16]

6. Francis R. Report of the Mid Staffordshire NHS Foundation Trust public inquiry: executive summary. London: HMSO; 2013.

7. Tregunno D, Ginsburg L, Clarke B, Norton P. Integrating patient safety into health professionals' curricula: a qualitative study of medical, nursing and pharmacy faculty perspectives. BMJ Qual Saf 2014;23:257-264.

8. Nie Y, Duan Y, Chen P, Barraclough B, Zhang M, Li J. Patient safety education for undergraduate medical students: a systematic review. Med Educ 2011;11(33):1-8.

9. Chenot TM, Daniel LG. Frameworks for patient safety in the nursing curriculum. J Nurs Educ 2010;49(1):559-68.

10. World Health Organisation. WHO Patient Safety Curriculum Guide: multiprofessional edition. Geneva, Switzerland: World Health Organisation; 2011.

11. Walton MM, Shaw T, Barnet S, Ross J. Developing a national patient safety education framework for Australia. Qual Saf Health Care 2006;15:437-442.

12. King J, Anderson CM. The Canadian interprofessional patient safety competencies: their role in healthcare professionals' education. J Patient Saf 2012;8:30-35.

13. McNulty JP, Rainford L, Bezzina P, Henner A, Kukkes T, Pronk-Larive D, Vandulek C. A picture of radiography education across Europe. Radiography 2016;22:5-11.

14. European Federation of Radiographer Societies. European qualifications frame- work (EQF) benchmarking document: radiographers. Utrecht, the Netherlands: European Federation of Radiographer Societies; 2014. Available from: http:// www.efrs.eu/uploads/files/550d4d65-9c48-4841-83c0-1b2450ace4bd.eqf\% 20benchmarking\%20document\%20-\%20radiographers_web.pdf [accessed 09.09.16]. 
15. European Federation of Radiographer Societies. EFRS statement on radiography education in Europe. Utrecht, the Netherlands: European Federation of Radiographer Societies; 2012. Available from: http://www.efrs.eu/publications [accessed 09.09.16].

16. Fincham JE. Response rates and responsiveness for surveys, standards, and the Journal. Am J Pharm Edu 2008;72(2):43.

17. European Commission. Council Directive 2013/59/Euratom on Basic Safety Standards. Official Journal of the European Union, 2014:57, L13. Available from: http://eurlex.europa.eu/legal-content/EN/TXT/HTML/?uri=OJ:L:2014:013:FULL\&from=EN [accessed 02.10.16].

18. Health and Care Professions Council. Standards of Proficiency: Radiographers. London, UK: Health and Care Professions Council; 2013. Available from: http://www.hpc-uk.org/registrants/standards/download/index.asp?id=51 [accessed 02.10.16].

19. CORU Radiographers Registration Board. Radiographers Registration Board Code of Professional Conduct and Ethics. Dublin, Ireland: CORU Radiographers Registration Board; $2013 . \quad$ Available from: http://www.coru.ie/en/about_us/radiographers_registration_board [accessed 02.10.16].

20. Bleiker J, Knapp KM, Frampton I. Teaching patient care to students: a blended learning approach in radiography education. Radiography 2011; 17(3):235-240.

21. Aura S, Jordan S, Saano S, Tossavainen K, Tutunen H. Transfer of learning: radiographers' perceptions of simulation-based educational intervention. Radiography 2016; 22(3):228-236.

22. Thornton RH, Dauer LT, Shuk E, Bylund CL, Banerjee SC, Maloney E, Fox LB, Beattie CM, Hricak H, Hay J. Patient perspectives and preferences for communication of medical imaging risks in a cancer care setting. Radiology 2015; 275(2):545-552.

23. European Society of Radiology EuroSafe Imaging. EuroSafe imaging call for action. Vienna, Austria: European Society of Radiology; 2014. Available from: http://www.eurosafeimaging.org/about/call-for-action [accessed 02.10.16].

24. World Health Organization. Communicating radiation risks in paediatric patients: information to support healthcare discussions about benefit and risk. Geneva, Switzerland: World Health Organization; 2016. Available from: http://www.who.int/ionizing_radiation/pub_meet/radiation-risks-paediatricimaging/en/ [accessed 02.10.16].

25. Bowman S. The radiographer/patient relationship - a short term but vital interaction. Radiography Today 1993; 59:675. 
26. Portelli JL, McNulty JP, Bezzina P, Rainford L. Radiographers' and radiology practitioners' opinion, experience and practice of benefit-risk communication and consent in paediatric imaging. Radiography 2016; In Press.

27. Portelli JL, McNulty JP, Bezzina P, Rainford L. Paediatric imaging radiation dose awareness and use of referral guidelines amongst radiology practitioners and radiographers. Insights Imaging 2016; 7(1):145-153.

28. European Federation of Radiographer Societies. EFRS Members. Utrecht, the Netherlands: European Federation of Radiographer Societies; 2016. Available from: http://www.efrs.eu/members [accessed 02.10.16]. 